\title{
White-Matter Hyperintensities and Lacunar Infarcts Are Associated with an Increased Risk of Alzheimer's Disease in the Elderly in China
}

\author{
Shuai Ye ${ }^{a}$, Shuyang Dong ${ }^{\mathrm{b}, \mathrm{c}}$ \\ Jun Tan ${ }^{d}$, Le Chen ${ }^{b, c}$, Hai Yang ${ }^{b}$ \\ Yang Chen ${ }^{\mathrm{b}}$, Zeyan Peng ${ }^{\mathrm{b}, \mathrm{c}}$ \\ Yingchao Huo ${ }^{b}$, Juan Liu ${ }^{\mathrm{b}}$ \\ Mingshan Tang ${ }^{\mathrm{e}}$, Yafei $\mathrm{Li}^{\mathrm{f}}$ \\ Huadong Zhou ${ }^{\mathrm{b}, \mathrm{g}}$, Yong Tao ${ }^{\mathrm{b}}$ \\ a'Battalion 3 of Cadet Brigade, Third \\ Military Medical University (Army Medical \\ University), Chongqing, China \\ bepartment of Neurology, Daping \\ Hospital, Third Military Medical University \\ (Army Medical University), \\ Chongqing, China \\ 'Postgraduate School, Bengbu Medical \\ College, Anhui, China \\ ${ }^{\mathrm{d}}$ Rashid Laboratory for Developmental \\ Neurobiology, Department of Psychiatry \\ and Behavioral Neurosciences, Morsan \\ College of Medicine, University of South \\ Florida, Tampa, FL, USA \\ eDepartment of Neurology, the People's \\ Hospital of Banan District, Chongqing, \\ China \\ fDepartment of Epidemiology, College of \\ Preventive Medicine, Third Military \\ Medical University (Army Medical \\ University), Chongqing, China \\ ${ }^{9}$ Department of Neurology, Qianjiang \\ National Hospital, Chongqing, China \\ Received April 5, 2018 \\ Revised July 17, 2018 \\ Accepted July 19, 2018

\section{Correspondence} \\ Huadong Zhou, MD, PhD \\ Department of Neurology, \\ Daping Hospital, \\ Third Military Medical University \\ (Army Medical University), \\ No. 10, Changjiang Branch Road, \\ Yuzhong District, Chongqing 400042, \\ China \\ Tel +86-23-68757851 \\ Fax +86-23-68711956 \\ E-mail zhouhuad@163.com \\ Yong Tao, MD \\ Department of Neurology, \\ Daping Hospital, \\ Third Military Medical University \\ (Army Medical University), \\ No. 10, Changjiang Branch Road, \\ Yuzhong District, Chongqing 400042, \\ China \\ Tel +86-23-68757851 \\ Fax +86-23-68711956 \\ E-mail taoyong8987@sina.com
}

Background and Purpose This study investigated the contribution of white-matter hyperintensities (WMH) and lacunar infarcts (LI) to the risk of Alzheimer's disease (AD) in an elderly cohort in China.

Methods Older adults who were initially cognitively normal were examined with MRI at baseline, and followed for 5 years. WMH were classified as mild, moderate, or severe, and LI were classified into a few LI (1 to 3 ) or many LI ( $\geq 4$ ). Cognitive function was assessed using the Mini Mental State Examination and the Activities of Daily Living scale.

Results Among the 2,626 subjects, 357 developed AD by the end of the 5-year follow-up period. After adjusting for age and other potential confounders, having only WMH, having only LI, and having both WMH and LI were associated with an increased risk of developing AD compared with having neither WMH nor LI. Moderate and severe WMH were associated with an increased risk of developing AD compared with no WMH. Furthermore, patients with many LI had an increased risk of developing AD compared with no LI.

Conclusions Having moderate or severe WMH and many LI were associated with an increased risk of developing $\mathrm{AD}$, with this being particularly striking when both WMH and LI were present.

Key Words Alzheimer's disease, small-vessel diseases, white-matter hyperintensities.

\section{INTRODUCTION}

Alzheimer's disease $(\mathrm{AD})$ is the most common form of dementia among the elderly and one of the most important health-care challenges in this population. There were reportedly 47 million people worldwide over the age of 60 living with dementia in 2015, and this is expected to increase to 131 million people by $2050 .^{1}$ There is increasing evidence that many risk factors increase the risk of $\mathrm{AD}$, including being older, low educational attainment, diabetes, hypertension, obesity, smoking, excessive alcohol consumption, and ApoE level..$^{2-4}$ It is possible that controlling the related risk factors could greatly reduce the prevalence of dementia, but this remains to be fully explored. ${ }^{5}$

Cerebral white-matter hyperintensities (WMH) are areas of increased signals in T2weighted and FLAIR MRI scans. The prevalence of WMH lesions increases with age, and is associated with arterial hypertension and arteriosclerosis. ${ }^{6,7}$ However, studies investigating the relationship between $\mathrm{WMH}$ and dementia have produced inconsistent results. Several studies have shown that WMH are associated with cognitive decline and dementia in the elderly population, ${ }^{8,9}$ while others have suggested that there are no such relationships. ${ }^{10}$ Lacu-

\footnotetext{
(c) This is an Open Access article distributed under the terms of the Creative Commons Attribution Non-Commercial License (https://creativecommons.org/licenses/by-nc/4.0) which permits unrestricted non-commercial use, distribution, and reproduction in any medium, provided the original work is properly cited.
} 
nar infarcts (LI) are small (3-20 $\mathrm{mm}$ in diameter), noncortical infarcts that are generally thought to be caused by the occlusion of the penetrating arteries. ${ }^{11}$ However, the association between $\mathrm{LI}$ and $\mathrm{AD}$ has received little attention. Both WMH and LI are small-vessel lesions, and cranial MRI suggests that the two diseases are highly prevalent in the elderly population. However, the relative impacts of WMH and LI on $\mathrm{AD}$ remain unclear.

In the present study we investigated the independent contributions of WMH and LI to the risk of developing $\mathrm{AD}$ in an elderly cohort in China. We also examined the associations of the severities of $\mathrm{WMH}$ and $\mathrm{LI}$ with the risk of developing $\mathrm{AD}$.

\section{METHODS}

\section{Study subjects}

The study population included subjects aged at least 60 years who were registered in the Neurology Department of Daping Hospital in Chongqing, China during 2009 and 2010. These subjects underwent brain MRI for the following reasons: transient ischemic attack, stroke, hypertension, diabetes, hyperlipidemia, dizziness, syncope, or headache. Patients with a diagnosis of dementia, a concomitant neurological disorder that could potentially affect cognitive function, a severe and persistent mental illness, or a history of head trauma were excluded from our study. Brain MRI was performed in 3,139 patients. After the initial examination, 261 patients were excluded, resulting in 2,878 patients being followed. The Institutional Review Board of Daping Hospital approved the protocol of this study, and all subjects provided informed consent (IRB No. ChiCTR-OCC-12001966).

\section{Clinical evaluation}

The collected demographic data included age, sex, height, weight, and education level, where $\leq 6$ years of schooling was considered to be a low education level and $>6$ years of schooling was considered to be a high education level. The vascular risk factors included in our analyses were hypertension, hyperlipidemia, diabetes, coronary artery disease, history of stroke, current smoking status, and daily alcohol consumption status. Blood samples were collected to measure the levels of glucose, lipids, high-sensitivity C-reactive protein, homocysteine, and ApoE. Hypertension, diabetes, hyperlipidemia, history of stroke, and coronary artery disease were diagnosed using the tenth revision of the International Classification of Diseases. The smoking status and the alcohol consumption status were classified as described previously. ${ }^{12}$

\section{Neuropsychological assessment}

The Chinese version of the Mini Mental State Examination
(MMSE) and the Activities of Daily Living (ADL) scale were used to measure the cognitive status, ${ }^{13}$ with cutoff scores of 24 and 16 points, respectively. A battery of neuropsychological examinations was further administered when the MMSE revealed cognitive decline. This battery included the Fuld Object Memory Evaluation to assess extensive cognitive dysfunction, ${ }^{14}$ Rapid Verbal Retrieval to assess semantic memory, ${ }^{15}$ the Wechsler Adult Intelligence Scale to assess immediate memory and graphical recognition, ${ }^{16}$ the Pfeiffer Outpatient Disability Questionnaire to evaluate the ability to engage in social activities, ${ }^{17}$ the Hamilton Depression Rating Scale to measure emotional status, ${ }^{18}$ and the Hachinski Ischemic Score (HIS) to detect significant vascular disease. ${ }^{19}$

\section{Diagnosing dementia}

A senior neurologist diagnosed $\mathrm{AD}$ according to our previously described protocol. ${ }^{13} \mathrm{AD}$ was diagnosed based on the updated clinical diagnostic criteria established by the National Institute on Aging and the Alzheimer's Association. ${ }^{20}$ The National Institute of Neurological Disorders and Stroke/Association Internationale pour la Recherche et l'Enseignement en Neurosciences criteria and the HIS were used to distinguish $\mathrm{AD}$ from vascular dementia (VaD) as follows: $\mathrm{HIS} \leq 4, \mathrm{AD}$; $4<\mathrm{HIS}<7$, mixed dementia; and HIS $\geq 7, \mathrm{VaD}^{21}$ Other dementias such as frontotemporal dementia (FTD) and dementia with Lewy bodies (DLB) were diagnosed based on the Diagnostic and Statistical Manual of Mental Disorders. ${ }^{22}$

\section{MRI analysis}

All subjects underwent MRI on a device with a 1.5-T magnet (Signa EXCITE HD, General Electric, Boston, MA, USA) using the following standard protocol: T1-weighted [repetition time (TR)/echo time (TE) $=450 / 8.9 \mathrm{~ms}$ ], T2-weighted (TR/ $\mathrm{TE}=5,000 / 87 \mathrm{~ms}$ ), and FLAIR (TR/TE $=8,500 / 88 \mathrm{~ms}$ and inversion time $=2,000 \mathrm{~ms}$ ) scans.

MRI was used to estimate the severity of WMH by rating a FLAIR sequence according to the Fazekas scale, followed by categorization into three severity classes: ${ }^{23}$ mild (punctate), moderate (early confluent), and severe (confluent). We avoided the confounding presence of focal WMH that were due to index stroke by simultaneously assessing T2-weighted and diffusion-weighted imaging sequences. LI were defined as areas of focal hyperintensity in a T2-weighted sequence that were $3-20 \mathrm{~mm}$ in diameter and located in the basal ganglia or subcortical white matter. Areas of WMH were also required to have corresponding prominent hypointensity in a T1-weighted sequence in order to distinguish LI from WMH. The number of LI was classified into a few LI (1 to 3 ) and many LI ( $\geq 4) .^{24}$ The presence of both WMH and LI was defined when WMH and LI existed together. 
Automatic quantification of intracranial volume, brain parenchyma volume, and WMH volume was performed using T2-weighted and FLAIR images with Software for Neuro-Image Processing in Experimental Research. ${ }^{25}$ A percentage measure reflecting the acquired loss of brain volume was calculated using the following equation:

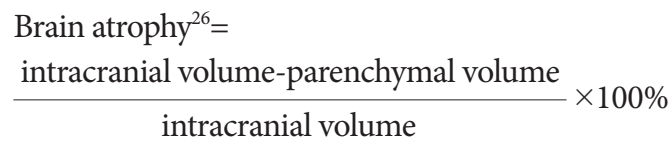

\section{Follow-up}

In total, 2,878 patients were followed for 5 years from January 2011 to December 2015. The same neuropsychological tests were performed annually by a neuropsychologist blinded to all clinical information.

\section{Statistical analysis}

The chi-square test and Fisher's exact test were used to analyze categorical data. Continuous data were analyzed with $t$ tests or one-way ANOVA followed by the Tukey's tau-b for multiple comparisons. Between-groups analyses of baseline variables were performed with a chi-square test, Fisher's exact test, $t$ test, and Mann-Whitney $\mathrm{U}$ test. The Cox proportionalhazards model was used to estimate hazard ratios (HRs) for AD. The models were first applied without adjusting for any relevant confounding factors. They were subsequently adjusted for the covariates that were chosen a priori, including age, sex, education level, hypertension, hyperlipidemia, diabetes, smoking status, alcohol consumption status, and ApoE level. All analyses were conducted using SPSS 19.0 for Windows (IBM Corp., Armonk, NY, USA).

\section{RESULTS}

\section{Baseline characteristics}

During the 5-year follow-up period, 89 of the patients died, 67 moved away, and 96 discontinued participation (57 with VaD, 13 with DLB, 7 with FTD, and the remaining 19 patients dropped out due to the presence of severe illnesses such as cardiac, hepatic, renal failure, or other systemic diseases), leaving 2,626 patients who completed the 5-year follow-up. AD was diagnosed in 357 (13.6\%) of these patients. MRI was performed at the end of the 5-year follow-up in 2009 (76.5\%) patients, of which 260 (72.8\%) patients were in the $\mathrm{AD}$ group, and 186 (71.5\%) patients were found to have brain atrophy.

The age of the patients was $66.3 \pm 8.1$ years (mean \pm SD) at baseline, and $51.6 \%$ of them were female. Among the 2,626 patients, only WMH were found in 856 (32.6\%) patients, only LI were found in 496 (18.9\%) patients, and both WMH and
LI were found in 407 (15.5\%) patients. The baseline characteristics of the study participants are summarized in Table 1. The patients with $\mathrm{AD}$ were older, more likely to be female and have a low education level, hypertension, hyperlipidemia, and diabetes, be current smokers and daily drinkers, and have higher plasma ApoE levels.

The severities of WMH and LI are compared between participants with and without $\mathrm{AD}$ in Table 2. At the end of the follow-up, 147 patients with WMH had developed AD, including 59 (36.6\%) with mild WMH, 50 (37.4\%) with moderate $\mathrm{WMH}$, and 38 (26.0\%) with severe WMH. Additionally, 80 patients with LI developed $\mathrm{AD}$, including 46 (43.0\%) with a few LI and 37 (34.6\%) with many LI. The severities of WMH and LI differed significantly between the patients who did and did not develop AD. Furthermore, significantly higher proportions of AD patients had only WMH, only LI, or both WMH and LI than neither WMH nor LI. The number of patients with WMH and LI had also increased at the end of the 5-year follow-up. Among $357 \mathrm{AD}$ patients, there had been 147 patients with only WMH at baseline, and this increased to 163 at the end of the follow-up; similarly, the number with only LI increased from 80 to 87 , and the number with both WMH and LI increased from 81 to 85 .

Table 1. Comparison of baseline characteristics between patients with and without $A D$

\begin{tabular}{lccc}
\hline \multicolumn{1}{c}{ Characteristic } & $\begin{array}{c}\text { No AD } \\
(\boldsymbol{n = 2 , 2 6 9 )}\end{array}$ & $\begin{array}{c}\text { AD } \\
(\boldsymbol{n}=\mathbf{3 5 7})\end{array}$ & $\boldsymbol{p}$ \\
\hline Demographics & & & \\
\hline Age, years & $65.4 \pm 7.8$ & $71.7 \pm 8.2$ & $<0.01$ \\
\hline Sex, female & $1,161(51.2)$ & $194(54.3)$ & $<0.05$ \\
\hline Low education level, $\leq 6$ years & $547(24.1)$ & $101(28.3)$ & $<0.01$ \\
\hline BMl, kg/m & $23.5 \pm 3.1$ & $24.1 \pm 3.2$ & 0.27 \\
\hline Vascular risk factors & & & \\
\hline Hypertension & $615(27.1)$ & $115(32.2)$ & $<0.01$ \\
\hline Hyperlipidemia & $517(22.8)$ & $96(26.9)$ & $<0.01$ \\
\hline Diabetes & $533(23.5)$ & $94(26.3)$ & $<0.05$ \\
\hline Current smoking & $361(15.9)$ & $67(18.8)$ & $<0.05$ \\
\hline Daily alcohol consumption & $309(13.6)$ & $59(16.5)$ & $<0.05$ \\
\hline Coronary artery disease & $329(14.5)$ & $59(16.5)$ & $<0.08$ \\
\hline History of stroke & $481(21.2)$ & $80(22.4)$ & $<0.18$ \\
\hline Blood indexes & & & \\
\hline ApoE, mg/L & $33.21 \pm 16.81$ & $35.41 \pm 14.23$ & $<0.05$ \\
\hline Hcy, mmol/L & $18.22 \pm 6.79$ & $18.97 \pm 8.01$ & $<0.12$ \\
\hline hs-CRP, mg/L & $5.61 \pm 1.24$ & $5.55 \pm 1.19$ & $<0.38$ \\
\hline Cognition assessment & & & \\
\hline MMSE score & $29.6 \pm 2.62$ & $28.8 \pm 2.32$ & $<0.15$ \\
\hline ADL score & $12.8 \pm 2.14$ & $13.4 \pm 2.43$ & $<0.13$ \\
\hline Da & & & \\
\hline
\end{tabular}

Data are mean \pm SD or $n(\%)$ values.

AD: Alzheimer's disease, ADL: Activities of Daily Living, BMl: body mass index, Hcy: homocysteine, hs-CRP: high-sensitivity C-reactive protein, MMSE: Mini Mental State Examination. 


\section{Associations of WMH and LI with AD}

The associations of $\mathrm{AD}$ with $\mathrm{WMH}$ and $\mathrm{LI}$ are presented in Table 3 for the Cox proportional-hazards regression model. After adjusting for age, sex, education level, hypertension, hyperlipidemia, diabetes, smoking status, alcohol consumption status, and ApoE level, moderate WMH (HR $=1.31,95 \%$ $\mathrm{CI}=1.27-1.52)$ and severe WMH $(\mathrm{HR}=1.75,95 \% \mathrm{CI}=1.37-$ 2.01) were associated with an increased risk of developing $A D$ when compared with no WMH. The presence of many LI ( $\mathrm{HR}=1.34,95 \% \mathrm{CI}=1.26-1.52)$ was also associated with an increased risk of developing $\mathrm{AD}$ when compared with no LI

Table 2. Comparison of severities of WMH and $\mathrm{LI}$ between patients with and without $A D$

\begin{tabular}{|c|c|c|c|}
\hline Characteristic & $\begin{array}{c}\text { No AD } \\
(n=2,269)\end{array}$ & $\begin{array}{c}\text { AD } \\
(n=357)\end{array}$ & $p$ \\
\hline WMH & & & $<0.01$ \\
\hline None & $1,560(68.7)$ & $210(58.8)$ & \\
\hline Mild & 366 (16.1) & $59(16.5)$ & \\
\hline Moderate & 217 (9.6) & $50(14.1)$ & \\
\hline Severe & $126(5.6)$ & 38 (10.6) & \\
\hline ㄴ & & & $<0.05$ \\
\hline None & $1,853(81.8)$ & $277(77.6)$ & \\
\hline A few (1 to 3 ) & $279(12.2)$ & 45 (12.6) & \\
\hline Many $(\geq 4)$ & $137(6.0)$ & $35(9.8)$ & \\
\hline WMH and LI & & & $<0.01$ \\
\hline Neither WMH nor LI & $818(36.1)$ & $49(13.7)$ & \\
\hline Only WMH & 709 (31.2) & $147(41.2)$ & \\
\hline Only LI & 416 (18.3) & $80(22.4)$ & \\
\hline Both WMH and $\mathrm{LI}$ & $326(14.4)$ & $81(22.7)$ & \\
\hline
\end{tabular}

Data are $n(\%)$ values.

AD: Alzheimer's disease, LI: lacunar infarcts, WMH: white-matter hyperintensities. after adjusting for confounding factors. Furthermore, the presence of only WMH $(\mathrm{HR}=1.40,95 \% \mathrm{CI}=1.25-1.59)$, the presence of only LI (HR=1.23, 95\% CI=1.14-1.39), and the presence of both WMH and LI (HR=2.03, 95\% CI=1.692.26) were found to be associated with an increased risk of developing $\mathrm{AD}$ when compared with the presence of neither WMH nor LI after adjusting for confounding factors.

\section{Incidence of $\mathrm{AD}$ according to age}

The age-stratified relationships of the presence of only WMH, only LI, and both $\mathrm{WMH}$ and $\mathrm{LI}$ with the incidence of $\mathrm{AD}$ are presented in Table 4. All patients were divided into three age groups: $60-69,70-79$, and $\geq 80$ years. A particularly interesting finding was that in each age group, the incidence of $\mathrm{AD}$ per 1,000 person-years was significantly higher in patients with only WMH, only LI, and both WMH and LI than in patients with neither WMH nor LI $(p<0.01)$. Furthermore, in each age group the incidence of $\mathrm{AD}$ per 1,000 person-years was significantly higher in patients with moderate or severe WMH than in patients with mild WMH ( $p<$ 0.01 ). Finally, the incidence of $A D$ per 1,000 person-years was also significantly higher in patients with many LI than in patients with a few LI $(p<0.05)$.

\section{Incidence of $\mathrm{AD}$ according to follow-up time}

Fig. 1 illustrates the incidence rates of $\mathrm{AD}$ in patients with only WMH, only LI, or both WMH and LI during the 5-year follow-up period. At the end of the follow-up period, the incidence of $\mathrm{AD}$ was significantly higher in patients with only WMH, only LI, or both WMH and LI than in those with neither WMH nor LI $(p<0.01)$.

Table 3. Associations of WMH and $\mathrm{LI}$ with $\mathrm{AD}$ in a Cox proportional-hazards regression model

\begin{tabular}{|c|c|c|c|c|}
\hline & Crude HR for AD (95\% Cl) & $p$ & Adjusted HR for AD $(95 \% \mathrm{CI})^{*}$ & $p$ \\
\hline \multicolumn{5}{|l|}{ WMH } \\
\hline None & 1 (reference) & & 1 (reference) & \\
\hline Mild & $1.17(0.93-1.26)$ & $>0.05$ & $1.14(0.91-1.23)$ & $>0.05$ \\
\hline Moderate & $1.33(1.23-1.54)$ & $<0.05$ & $1.31(1.27-1.52)$ & $<0.05$ \\
\hline Severe & $1.78(1.41-2.02)$ & $<0.01$ & $1.75(1.37-2.01)$ & $<0.01$ \\
\hline \multicolumn{5}{|l|}{ LI } \\
\hline None & 1 (reference) & & 1 (reference) & \\
\hline A few (1 to 3 ) & $1.09(0.85-1.17)$ & $>0.05$ & $1.06(0.82-1.14)$ & $>0.05$ \\
\hline Many $(\geq 4)$ & $1.37(1.25-1.54)$ & $<0.05$ & $1.34(1.26-1.52)$ & $<0.05$ \\
\hline \multicolumn{5}{|l|}{ WMH and LI } \\
\hline Neither WMH nor LI & 1 (reference) & & 1 (reference) & \\
\hline Only WMH & $1.44(1.24-1.62)$ & $<0.01$ & $1.40(1.25-1.59)$ & $<0.01$ \\
\hline Only LI & $1.26(1.12-1.37)$ & $<0.05$ & $1.23(1.14-1.39)$ & $<0.05$ \\
\hline Both WMH and LI & $2.05(1.67-2.28)$ & $<0.01$ & $2.03(1.69-2.26)$ & $<0.01$ \\
\hline
\end{tabular}

${ }^{*}$ Adjusted for age, sex, education level, hypertension, hyperlipidemia, diabetes, smoking status, alcohol consumption status, and ApoE level.

AD: Alzheimer's disease, HR: hazard ratio, LI: lacunar infarcts, WMH: white-matter hyperintensities. 
Table 4. Relationships of WMH and $\mathrm{LI}$ with the incidence of $\mathrm{AD}$ according to age

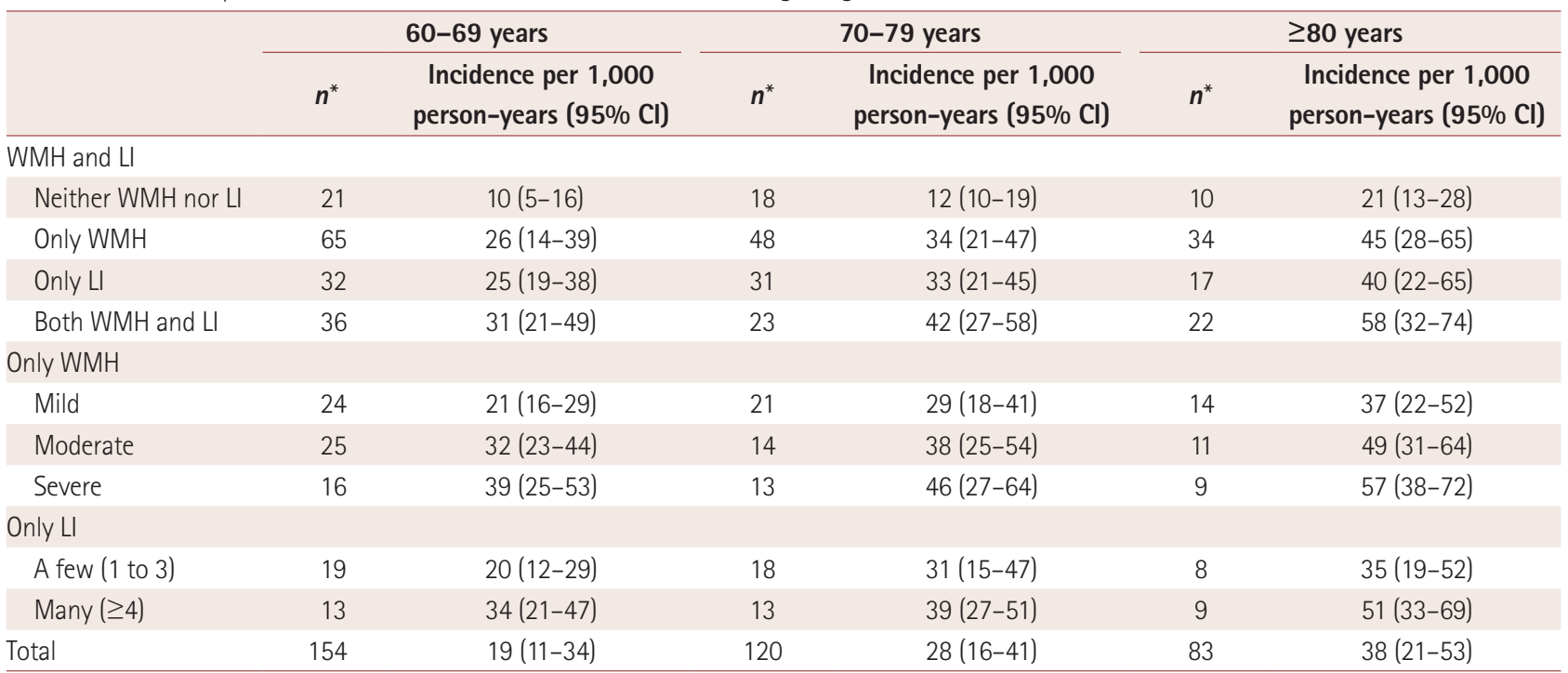

*The number of $A D$ cases.

AD: Alzheimer's disease, LI: lacunar infarcts, WMH: white-matter hyperintensities.

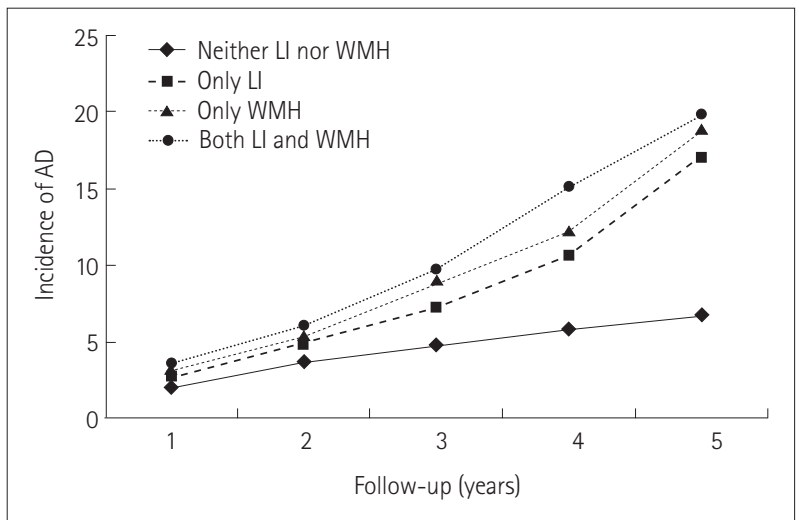

Fig. 1. Incidence of AD during the 5-year follow-up. At the end of the follow-up, the incidence of $A D$ dementia was significantly higher in patients with only $\mathrm{WMH}_{\text {, only }} \mathrm{LI}$, and both $\mathrm{WMH}$ and $\mathrm{LI}$ than in those with neither WMH nor LI ( $p<0.01)$. AD: Alzheimer's disease, LI: lacunar infarcts, WMH: white-matter hyperintensities.

\section{Cognitive function scores according to WMH and LI} Fig. 2 shows the MMSE and ADL scores in patients with only WMH, only LI, or both WMH and LI at the end of the follow-up. Patients with only WMH, only LI, or both WMH and LI had significantly lower MMSE scores than those with neither WMH nor LI $(p<0.01)$ (Fig. 2A). In addition, patients with only WMH, only LI, or both WMH and LI had significantly higher ADL scores than those with neither WMH nor LI $(p<0.01)$ (Fig. 2B).

\section{DISCUSSION}

Previous studies have found an association between WMH and $\mathrm{AD}^{27}$ The Cardiovascular Health Cognition Study investigated the relationship between WMH and the risk of dementia in 3,608 participants who underwent MRI examinations of the skull over an 8-year follow-up period. ${ }^{28}$ That study found that participants with a higher severity of WMH had an increased risk of developing clinical dementia (HR= 2.0, 95\% CI $1.63-2.37$ ). The Rotterdam Scan Study also found WMH to be strongly associated with an increased risk of developing dementia. ${ }^{29}$ Another longitudinal study of 85 patients with uncomplicated $\mathrm{AD}$ conducted over a 6-month follow-up period found that WMH were associated with a greater degree of cognitive impairment in patients with $\mathrm{AD} .^{30}$ However, another study found that there was no significant association between WMH and the risk of clinical dementia in 204 participants who were followed as part of the OsakiTajiri Project over a 5-year period. ${ }^{10}$ The present prospective and large-sample study found that moderate and severe WMH were associated with an increased risk of developing AD.

Few studies have directly investigated the relationship between LI and the risk of developing dementia. ${ }^{31,32}$ Kitagawa et al. ${ }^{31}$ retrospectively examined the impact of LI on the incidence of dementia in 1,106 patients with vascular risk factors, and found a significant association between LI and dementia after adjusting for relevant confounding factors. Vermeer et al. ${ }^{32}$ prospectively examined the association between $\mathrm{LI}$ and the risk of dementia in 1,015 participants aged $60-90$ years and free of dementia at baseline, and found LI to be strongly associated with an increased risk of the development of dementia over time. Our results also suggest that patients with many LI have an increased risk of AD. 
were followed for 3 years, and found hypertension, diabetes, hyperlipidemia, stroke, and coronary artery disease to be common comorbidities in patients with AD. In the present study, both WMH and LI were associated with a higher risk of developing $\mathrm{AD}$ compared with only WMH and only LI, suggesting that WMH and LI exert certain synergistic effects on the development of $\mathrm{AD}$. These effects might be due to $\mathrm{WMH}$ being associated with global neurocognitive deficits and psychomotor speed, ${ }^{36}$ whereas LI individually contribute to a significant deterioration of domain-specific impairments such as mental and motor speed, and executive functions. ${ }^{37}$ Therefore, patients with both WMH and LI simultaneously will have even greater cognitive impairment, which markedly increases the risk of clinical dementia.

Cerebral WMH involve axonal loss and demyelination, and their pathogenesis is thought to be due to ischemia related to small-vessel diseases. However, WMH may also result from the consequences of cortical AD pathology [i.e., beta-amyloid $(\mathrm{A} \beta)$ deposition and hyperphosphorylated tau]. ${ }^{38-40}$ To elucidate the association between WMH and the progression of $\mathrm{A} \beta$ deposition in patients with $\mathrm{AD}$, Grimmer et al..$^{39}$ performed FLAIR MRI and $\left[{ }^{11} \mathrm{C}\right] \mathrm{PiB}$ PET after a 28 -month follow-up of 22 patients with probable $\mathrm{AD}$ at baseline. Their longitudinal analysis revealed a statistically significant association between WMH and the progression of the A $\beta$ load $(p=0.006)$. Another study that used postmortem MRI showed that an increase in the cortical hyperphosphorylated tau burden independently predicted the severity of WMH in the pathogenesis of WMH damage..$^{40}$ The findings of that study also suggested that the presence of WMH is a marker for cortical AD-associated pathology rather than small-vessel disease in clinical dementia patients.

Several studies have also demonstrated an association between LI and AD. ${ }^{41,42}$ One study found an association between small-vessel disease and $\mathrm{AD}$ pathology, which was further associated with cognitive decline and dementia over 13year time period (from January 2002 to December 2012). ${ }^{41}$ Another study examined the associations of WMH and LI with the CSF levels of $A \beta 42$ and phosphorylated tau in 914 consecutive patients for which CSF and MRI scans were available, with the results showing that the deposition of amyloid was aggravated in patients with cerebral small-vessel disease. Another cross-sectional study demonstrated that the presence of LI was tightly coupled to an increase in the plasma $A \beta 40$ concentration in patients with $\mathrm{AD} .^{42}$

The strengths of the present study are that it included a large number of elderly people from the general population, its prospective design, and to it being (to our knowledge) the first study to investigate the associations of WMH, LI, and their synergistic effects with an increased risk of developing AD. 
However, this study was subject to some limitations. First, we did not use magnetic resonance diffusion-tensor imaging (DTI) to detect damage to the white matter. DTI is a new method for revealing the structure of white matter in the brain that can detect subtle WMH in white-matter tracts. ${ }^{43}$ Using DTI to observe changes in these tracts might have demonstrated a more-robust relationship between $\mathrm{WMH}$ and the risk of developing AD. Second, previous studies have suggested that periventricular WMH play an independent role in the development of dementia, especially with regards to $\mathrm{AD}^{44}$ and we did not divide WMH into periventricular WMH and deep WMH in our analyses. Third, the severity of LI as well as their distribution (i.e., whether they are found in the subcortex, cerebral cortex, brainstem, or cerebellum) have been shown to be related to the risk of cognitive decline. ${ }^{45,46}$ However, we did not examine the relationship between the distribution of LI and the risk of developing AD. Fourth, previous studies have suggested that WMH and LI exert different effects on cognitive function. Although this study evaluated various cognitive functions, such as semantic memory and transient memory, the associations of WMH and LI with various cognitive impairments were not assessed. Establishing relationships of LI and WMH with cognitive decline in specific cognitive areas would be highly significant to revealing the correlations of LI and WMH with the increased risk of developing AD. Fifth, this observational study only investigated the associations of WMH, LI, and their synergistic effects with the development of $\mathrm{AD}$, and did not further explore the impact of medication on the development of AD. Finally, changes in the A $\beta$ level in CSF have been shown to be associated with risk of developing $\mathrm{AD},{ }^{47}$ and some studies have revealed that such level changes are also associated with $\mathrm{WMH}^{48}$ However, we did not detect changes in the $\mathrm{A} \beta$ level in CSF.

In conclusion, this large-sample, prospective clinical study has demonstrated that WMH and LI are associated with the risk of developing $\mathrm{AD}$. The results suggest that controlling the progression of brain white-matter lesions and cavities may reduce the risk of developing $\mathrm{AD}$. The mechanisms underlying how WMH and LI lead to the development of $\mathrm{AD}$ warrant further investigations.

\section{Conflicts of Interest}

The authors have no financial conflicts of interest.

\section{Acknowledgements}

This study was supported by grants from the National Natural Science Foundation of China (81571258).

The authors would like to thank and acknowledge all of the participants who were enrolled in the study.

\section{REFERENCES}

1. Baumgart M, Snyder HM, Carrillo MC, Fazio S, Kim H, Johns H.
Summary of the evidence on modifiable risk factors for cognitive decline and dementia: a population-based perspective. Alzheimers Dement 2015;11:718-726.

2. Huang CC, Chung CM, Leu HB, Lin LY, Chiu CC, Hsu CY, et al. Diabetes mellitus and the risk of Alzheimer's disease: a nationwide population-based study. PLoS One 2014;9:e87095.

3. de la Torre JC. Cardiovascular risk factors promote brain hypoperfusion leading to cognitive decline and dementia. Cardiovasc Psychiatry Neurol 2012;2012:367516.

4. Norton S, Matthews FE, Barnes DE, Yaffe K, Brayne C. Potential for primary prevention of Alzheimer's disease: an analysis of populationbased data. Lancet Neurol 2014;13:788-794.

5. Ballard C, Gauthier S, Corbett A, Brayne C, Aarsland D, Jones E. Alzheimer's disease. Lancet 2011;377:1019-1031.

6. Scott JA, Braskie MN, Tosun D, Thompson PM, Weiner M, DeCarli C, et al. Cerebral amyloid and hypertension are independently associated with white matter lesions in elderly. Front Aging Neurosci 2015;7:221.

7. Park JH, Ovbiagele B. Response to the comment 'conflicting evidence on the association of white matter hyperintensities with large-artery disease.' Eur J Neurol 2015;22:e81.

8. Nolze-Charron G, Mouiha A, Duchesne S, Bocti C; Alzheimer's Disease Neuroimaging Initiative. White matter hyperintensities in mild cognitive impairment and lower risk of cognitive decline. J Alzheimers Dis 2015;46:855-862.

9. Altamura C, Scrascia F, Quattrocchi CC, Errante Y, Gangemi E, Curcio G, et al. Regional MRI diffusion, white-matter hyperintensities, and cognitive function in Alzheimer's disease and vascular dementia. J Clin Neurol 2016;12:201-208.

10. Meguro K, Ishii H, Kasuya M, Akanuma K, Meguro M, Kasai M, et al. Incidence of dementia and associated risk factors in Japan: The OsakiTajiri Project. J Neurol Sci 2007;260:175-182.

11. Zhang X, Ding L, Yuan J, Qin W, Hu W. Spatial relationship between acute lacunar infarction and white matter hyperintensities. Eur Neurol 2015;74:259-266.

12. Zhou S, Zhou R, Zhong T, Li R, Tan J, Zhou H. Association of smoking and alcohol drinking with dementia risk among elderly men in China. Curr Alzheimer Res 2014;11:899-907.

13. Zhou DH, Wang JY, Li J, Deng J, Gao C, Chen M. Study on frequency and predictors of dementia after ischemic stroke: the Chongqing stroke study. J Neurol 2004;251:421-427.

14. Fuld PA. The fuld object-memory evaluation. Chicago: Stoelting Instrument Co., 1981.

15. Zhang M, Qu G, Wang Z, Cai G, Katzman R, Simon D, et al. Prevalence study on dementia and Alzheimer disease. Zhonghua Yi Xue Za Zhi 1990;70:424-428.

16. Welsh KA, Butters N, Hughes JP, Mohs RC, Heyman A. Detection and staging of dementia in Alzheimer's disease. Use of the neuropsychological measures developed for the Consortium to Establish a Registry for Alzheimer's Disease. Arch Neurol 1992;49:448-452.

17. Pfeiffer E. A short portable mental status questionnaire for the assessment of organic brain deficit in elderly patients. J Am Geriatr Soc 1975; 23:433-441.

18. Hamilton M. A rating scale for depression. J Neurol Neurosurg Psychiatry 1960;23:56-62.

19. Hachinski V, Iadecola C, Petersen RC, Breteler MM, Nyenhuis DL, Black SE, et al. National Institute of Neurological Disorders and StrokeCanadian Stroke Network vascular cognitive impairment harmonization standards. Stroke 2006;37:2220-2241.

20. McKhann GM, Knopman DS, Chertkow H, Hyman BT, Jack CR Jr, Kawas $\mathrm{CH}$, et al. The diagnosis of dementia due to Alzheimer's disease: recommendations from the National Institute on Aging-Alzheimer's Association workgroups on diagnostic guidelines for Alzheimer's disease. Alzheimers Dement 2011;7:263-269.

21. Román GC, Tatemichi TK, Erkinjuntti T, Cummings JL, Masdeu JC, Garcia JH, et al. Vascular dementia: diagnostic criteria for research 
of Chinese population. Am J Alzheimers Dis Other Demen 2014;29: 521-525.

studies. Report of the NINDS-AIREN International Workshop. Neurology 1993;43:250-260.

22. American Psychiatric Association. Diagnostic and statistical manual of mental disorders: DSM-IV-TR. 4th ed. Washington: American Psychiatric Association, 2000.

23. Fazekas F, Chawluk JB, Alavi A, Hurtig HI, Zimmerman RA. MR signal abnormalities at $1.5 \mathrm{~T}$ in Alzheimer's dementia and normal aging. AJR Am J Roentgenol 1987;149:351-356.

24. van der Flier WM, van Straaten EC, Barkhof F, Verdelho A, Madureira $\mathrm{S}$, Pantoni L, et al. Small vessel disease and general cognitive function in nondisabled elderly: the LADIS study. Stroke 2005;36:2116-2120.

25. Admiraal-Behloul F, van den Heuvel DM, Olofsen H, van Osch MJ, van der Grond J, van Buchem MA, et al. Fully automatic segmentation of white matter hyperintensities in MR images of the elderly. Neuroimage 2005;28:607-617.

26. van der Flier WM, van den Heuvel DM, Weverling-Rijnsburger AW, Bollen EL, Westendorp RG, van Buchem MA, et al. Magnetization transfer imaging in normal aging, mild cognitive impairment, and Alzheimer's disease. Ann Neurol 2002;52:62-67.

27. Brickman AM, Zahodne LB, Guzman VA, Narkhede A, Meier IB, Griffith EY, et al. Reconsidering harbingers of dementia: progression of parietal lobe white matter hyperintensities predicts Alzheimer's disease incidence. Neurobiol Aging 2015;36:27-32.

28. Kuller LH, Lopez OL, Newman A, Beauchamp NJ, Burke G, Dulberg $\mathrm{C}$, et al. Risk factors for dementia in the cardiovascular health cognition study. Neuroepidemiology 2003;22:13-22.

29. Prins ND, van Dijk EJ, den Heijer T, Vermeer SE, Koudstaal PJ, Oudkerk $\mathrm{M}$, et al. Cerebral white matter lesions and the risk of dementia. Arch Neurol 2004;61:1531-1534.

30. Diaz JF, Merskey H, Hachinski VC, Lee DH, Boniferro M, Wong CJ, et al. Improved recognition of leukoaraiosis and cognitive impairment in Alzheimer's disease. Arch Neurol 1991;48:1022-1025.

31. Kitagawa K, Miwa K, Yagita Y, Okazaki S, Sakaguchi M, Mochizuki $\mathrm{H}$. Association between carotid stenosis or lacunar infarction and incident dementia in patients with vascular risk factors. Eur J Neurol 2015; 22:187-192.

32. Vermeer SE, Prins ND, den Heijer T, Hofman A, Koudstaal PJ, Breteler MM. Silent brain infarcts and the risk of dementia and cognitive decline. N Engl J Med 2003;348:1215-1222.

33. Wardlaw JM, Allerhand M, Doubal FN, Valdes Hernandez M, Morris $\mathrm{Z}$, Gow AJ, et al. Vascular risk factors, large-artery atheroma, and brain white matter hyperintensities. Neurology 2014;82:1331-1338.

34. Rutten-Jacobs LC, Markus HS; UK Young Lacunar Stroke DNA Study. Vascular risk factor profiles differ between magnetic resonance imaging-defined subtypes of younger-onset lacunar stroke. Stroke 2017;48: 2405-2411.

35. Qiao J, Lu WH, Wang J, Guo XJ, Qu QM. Vascular risk factors aggravate the progression of Alzheimer's disease: a 3-year follow-up study
36. Xu X, Hilal S, Collinson SL, Chong EJ, Ikram MK, Venketasubramanian $\mathrm{N}$, et al. Association of magnetic resonance imaging markers of cerebrovascular disease burden and cognition. Stroke 2015;46:28082814.

37. Jokinen H, Gouw AA, Madureira S, Ylikoski R, van Straaten EC, van der Flier WM, et al. Incident lacunes influence cognitive decline: the LADIS study. Neurology 2011;76:1872-1878.

38. McAleese KE, Walker L, Graham S, Moya EL, Johnson M, Erskine D, et al. Parietal white matter lesions in Alzheimer's disease are associated with cortical neurodegenerative pathology, but not with small vessel disease. Acta Neuropathol 2017;134:459-473.

39. Grimmer T, Faust M, Auer F, Alexopoulos P, Förstl H, Henriksen G, et al. White matter hyperintensities predict amyloid increase in Alzheimer's disease. Neurobiol Aging 2012;33:2766-2773.

40. McAleese KE, Firbank M, Dey M, Colloby SJ, Walker L, Johnson M, et al. Cortical tau load is associated with white matter hyperintensities. Acta Neuropathol Commun 2015;3:60. Wattjes MP, et al. Associations between cerebral small-vessel disease and Alzheimer disease pathology as measured by cerebrospinal fluid biomarkers. JAMA Neurol 2014;71:855-862.

42. Gurol ME, Irizarry MC, Smith EE, Raju S, Diaz-Arrastia R, Bottiglieri $\mathrm{T}$, et al. Plasma beta-amyloid and white matter lesions in AD, MCI, and cerebral amyloid angiopathy. Neurology 2006;66:23-29.

43. Pelletier A, Periot O, Dilharreguy B, Hiba B, Bordessoules M, Chanraud $\mathrm{S}$, et al. Age-related modifications of diffusion tensor imaging parameters and white matter hyperintensities as inter-dependent processes. Front Aging Neurosci 2016;7:255.

44. Kim S, Choi SH, Lee YM, Kim MJ, Kim YD, Kim JY, et al. Periventricular white matter hyperintensities and the risk of dementia: a CREDOS study. Int Psychogeriatr 2015;27:2069-2077.

45. Chen Y, Wang J, Zhang J, Zhang T, Chen K, Fleisher A, et al. Aberrant functional networks connectivity and structural atrophy in silent lacunar infarcts: relationship with cognitive impairments. J Alzheimers Dis 2014;42:841-850.

46. Nho K, Saykin AJ; Alzheimer's Disease Neuroimaging Initiative, Nelson PT. Hippocampal sclerosis of aging, a common Alzheimer's disease 'mimic': risk genotypes are associated with brain atrophy outside the temporal lobe. J Alzheimers Dis 2016;52:373-383.

47. Hardy J, Selkoe DJ. The amyloid hypothesis of Alzheimer's disease: progress and problems on the road to therapeutics. Science 2002;297: 353-356.

48. Roseborough A, Ramirez J, Black SE, Edwards JD. Associations beview. Alzheimers Dement 2017;13:1154-1167.
41. Kester MI, Goos JD, Teunissen CE, Benedictus MR, Bouwman FH, tween amyloid $\beta$ and white matter hyperintensities: a systematic re- 